\title{
Abundances of Hydrogen and Helium Isotopes in Jupiter
}

\author{
Adam Nolte and Cara Lietz \\ Chemical Engineering Department, University of Missouri, Rolla, MO 65401, USA
}

nolte@umr.edu

\begin{abstract}
Abundances of hydrogen and helium isotopes in Jupiter and other giant planets can answer important questions on the origin of elements in the solar system and the nature of processes in the sun. The Galileo Probe entered Jupiter in late 1995. In January of 1998, raw data from the Galileo Probe Mass Spectrometer (GPMS) were placed on the internet at the website that is given below: http://webserver.gsfc.nasa.gov/code915/gpms/datasets/gpmsdata.html. From the raw data we estimate values of ${ }^{3} \mathrm{He} /{ }^{4} \mathrm{He}=(2.17 \pm 0.03) \times 10^{-4}$ and ${ }^{2} \mathrm{H} /{ }^{1} \mathrm{H}^{\sim} 1.0 \times 10^{-4}$. These are higher than expected if the solar system formed from a homogeneous nebula (Wood, 1999) with subsequent production of excess ${ }^{3} \mathrm{He}$ by deuterium burning in the sun (Geiss, 1993). It appears that Jupiter formed instead from elements with some of the same chemical and isotopic irregu larities observed in meteorites.
\end{abstract}

\section{INTRODUCTION}

Niemann et al. (1996) reported values of ${ }^{4} \mathrm{He} / \mathrm{H}_{2}=0.156 \pm 0.006,{ }^{3} \mathrm{He} /{ }^{4} \mathrm{He}=(1.1 \pm 0.1) \times 10^{-4}$, and ${ }^{2} \mathrm{H} /{ }^{1} \mathrm{H}=(5 \pm 2) \times 10^{-5}$ for the abundances of these four lightest nuclides in Jupiter. Values for these isotope ratios in Jupiter were later changed to ${ }^{3} \mathrm{He} /{ }^{4} \mathrm{He}=(1.66 \pm 0.05) \times 10^{-4}$ and ${ }^{2} \mathrm{H} /{ }^{1} \mathrm{H}=(2.6$ $\pm 0.7) \times 10^{-5}$ (Mahaffy et al., 1998). Because of the importance of these measurements to our understanding of the origin of elements in the solar system, this note re-examines key experimental data that form the basis for these reports.

In the solar wind the ${ }^{3} \mathrm{He} /{ }^{4} \mathrm{He}$ ratio is higher and the ${ }^{2} \mathrm{H} /{ }^{1} \mathrm{H}$ ratio is lower than the values reported in Jupiter. Niemann et al. (1996) and Mahaffy et al. (1998) suggest that differences in these isotopic ratios are consistent with the nebular model for forming the solar system (Wood, 1999) and with the production of ${ }^{3} \mathrm{He}$ by deuterium burning in the sun (Geiss, 1993). According to this model, Jupiter and the sun formed out of the same nebular material, but lighter mass isotopes of hydrogen and helium are now enriched in the solar wind because deuterium burning in the sun converted ${ }^{2} \mathrm{H}$ into ${ }^{3} \mathrm{He}$.

Deuterium burning in the Sun seems likely, but another process may have produced the high ${ }^{3} \mathrm{He} /{ }^{4} \mathrm{He}$ ratio in the solar wind. Manuel and Hwaung (1983) pointed out that the lighter isotopes of all five noble gases, $\mathrm{He}, \mathrm{Ne}, \mathrm{Ar}, \mathrm{Kr}$, and $\mathrm{Xe}$, are systematically enriched in the solar wind. The enrichment is only 4\% per amu for Xe isotopes (Kaiser, 1972; Bernatowicz and Podosek, 1978) but steadily increases for lighter elements, becoming $27 \%$ per amu for Ne isotopes and $200 \%$ per amu for He isotopes. Such a mass-dependent fractionation pattern is expected from thermal diffusion in an ionized gas. Chapman and Cowling (1952, Section 14.71, p. 255) note that, "This must happen in the sun and the stars, where thermal diffusion will assist pressure diffusion in concentrating the heavier nuclei towards the hot central regions."

According to this model, diffusion enriches lighter isotopes of each element and lighter weight elements like $\mathrm{H}$ and $\mathrm{He}$ at the solar surface. Thus, the $\mathrm{H}$, He-rich solar skin may hide an interior of Fe, $\mathrm{Ni}, \mathrm{O}, \mathrm{Si}, \mathrm{S}$ and $\mathrm{Mg}$ (Manuel and Hwaung, 1983). These abundant elements of the 
inner planets may also be major components of the solar interior, which contains $99.8 \%$ of all solar system material (Wiens et al., 1999).

In the following sections we re-examine the experimental basis for reported abundances of ${ }^{1} \mathrm{H},{ }^{2} \mathrm{H},{ }^{3} \mathrm{He}$ and ${ }^{4} \mathrm{He}$ in Jupiter and compare them with solar abundances to evaluate the merits of these two models. As noted above, abundances of these four lightest stable nuclides may contain a record of the origin and abundance of elements in the solar system and the nature of processes in the sun.

It should be noted that the isotope ratios reported here are based solely on the raw GPMS data reported on the website. We did not have access to instrumental mass discrimination for the GPMS when the measurements shown in Tables 1 and 2 were made. We also were unable to obtain information on the source of the GPMS signal at 4 amu when the instrument was operated at $15 \mathrm{eV}$ (Table 2) to prevent ionization of He.

\section{EXPERIMENTAL DATA}

Both Niemann et al. (1996) and Mahaffy et al. (1998) note that counts at 3 amu are a mixture of $\mathrm{HD}^{+},{ }^{3} \mathrm{He}^{+}$and $\mathrm{H}_{3}{ }^{+}$ions. Niemann et al. (1996) report that the value of ${ }^{3} \mathrm{He} /{ }^{4} \mathrm{He}=$ $(1.1 \pm 0.1) \times 10^{-4}$ in Jupiter was determined from $3 \mathrm{amu}$ and $4 \mathrm{amu}$ data obtained with the noble gas cell (NGC) sample. They note that hydrogen was effectively absent from this gas sample. Mahaffy et al. (1998) report that the value of ${ }^{3} \mathrm{He} /{ }^{4} \mathrm{He}=(1.66 \pm 0.04) \times 10^{-4}$ in Jupiter was determined from $3 \mathrm{amu}, 4 \mathrm{amu}$ and $16 \mathrm{amu}$ (or $12 \mathrm{amu}$ ) data from NGC, from the first enrichment cell (EC1), and from calibration data of the Flight Unit (FU). They note that methane and noble gases are major components of the NGC sample.

The value of the ${ }^{3} \mathrm{He} /{ }^{4} \mathrm{He}$ ratio in Jupiter is best defined by the NGC sample. These NGC gases were collected through the first direct leak (DL1) into the first enrichment cell (EC1), where getter pumps were used to eliminate hydrogen and other chemically active species from the NGC sample. The mass spectrometer was isolated from atmospheric gases leaking directly into instrument during the analysis of NGC and EC1 gases. Data from the second enrichment cell (EC2) are less useful in defining the ${ }^{3} \mathrm{He} /{ }^{4} \mathrm{He}$ ratio because a direct leak of atmospheric gases into the mass spectrometer continued during the analysis of those gases.

Table 1 shows spectra over the mass range of 24 amu from the Galileo Probe Mass Spectrometer (GPMS) for gases from EC1. The first column on Table 1 gives the step number. The second column gives the mass/charge ratio, $\mathrm{m} / \mathrm{z}$. The third column gives the number of counts obtained. The ionizing potential was $75 \mathrm{eV}$ for all of the data shown in Table 1. The first six scans (steps 2165-2232) in Table 1 show the mass spectra of the "gettered" gases from NGC. There was very little hydrogen, but abundant helium, in this NGC sample. Thus, column 5 of Table 1 shows the lowest observed values for the ratio of counts at $(\mathrm{m} / \mathrm{z}=2)$ relative to those at $(\mathrm{m} / \mathrm{z}=4)$. The last two scans (steps 2775-2940) in Table 1 include gases released when the cell was heated to drive off some of the hydrogen trapped there.

Jupiter consists mostly of hydrogen and helium. Thus, the $\mathrm{H}_{2}{ }^{+}$ion is responsible for essentially all counts at $\mathrm{m} / \mathrm{z}=2$. Likewise, the ${ }^{4} \mathrm{He}^{+}$ion is responsible for essentially all counts at $\mathrm{m} / \mathrm{z}=4$. However, the counts at $\mathrm{m} / \mathrm{q}=3$ are expected to be a mixture of ${ }^{3} \mathrm{He}^{+}$, $\mathrm{HD}^{+}$, and perhaps $\mathrm{H}_{3}{ }^{+}$(Niemann et al., 1996; Mahaffy et al., 1998).

The last two columns in Table 1 show values of count ratios for $(\mathrm{m} / \mathrm{z}=3) /(\mathrm{m} / \mathrm{z}=4)$ and $(\mathrm{m} / \mathrm{z}=2) /(\mathrm{m} / \mathrm{z}=4)$. It can be seen that the $(\mathrm{m} / \mathrm{z}=3) /(\mathrm{m} / \mathrm{z}=4)$ count ratio increased from a 
value of $\sim 2.5 \times 10^{-4}$ to $\sim 2.7 \times 10^{-4}$ to $\sim 16 \times 10^{-4}$ as the value of the $(\mathrm{m} / \mathrm{z}=2) /(\mathrm{m} / \mathrm{z}=4)$ count ratio increased from a value of $\sim 0.0005$ to $\sim 0.0010$ to $\sim 0.035$. A time span of 6.45 minutes is represented by steps 2165-2940 tabulated in Table 1.

The data in Table 1 are valuable for determining the ${ }^{3} \mathrm{He} /{ }^{4} \mathrm{He}$ ratio because hydrogen is essentially absent. Likewise, other data are most useful for determining the $\mathrm{HD} / \mathrm{H}_{2}$ ratio when helium is essentially absent. This was accomplished by reducing the ionizing voltage potential below 24.48 electron volts, the first ionization potential of He.

Table 1. Data from NGC and ECl of the GPMS at $75 \mathrm{eV}$ for species at $\mathrm{m} / z=2,3$ and 4

\begin{tabular}{|c|c|c|c|c|}
\hline $\begin{array}{c}\text { Step } \\
\text { Number }\end{array}$ & $\begin{array}{c}\text { Mass/charge, } \\
\mathrm{m} / \mathrm{z}\end{array}$ & Counts & $\begin{array}{c}(m / z=3) /(m / z=4) \\
\times 10^{4}\end{array}$ & $\begin{array}{c}(m / z=2) /(m / z=4) \\
\times 10^{4}\end{array}$ \\
\hline 2165 & 2 & 3102 & \multirow{3}{*}{2.545} & \multirow{3}{*}{5.191} \\
\hline 2166 & 3 & 1521 & & \\
\hline 2167 & 4 & 5976064 & & \\
\hline 2253 & 2 & 8028 & \multirow{3}{*}{2.767} & \multirow{3}{*}{9.854} \\
\hline 2254 & 3 & 2254 & & \\
\hline 2255 & 4 & 8146944 & & \\
\hline 2278 & 2 & 8084 & \multirow{3}{*}{2.744} & \multirow{3}{*}{9.983} \\
\hline 2279 & 3 & 2222 & & \\
\hline 2280 & 4 & 8097792 & & \\
\hline 2288 & 2 & 7964 & \multirow{3}{*}{2.714} & \multirow{3}{*}{9.746} \\
\hline 2289 & 3 & 2218 & & \\
\hline 2290 & 4 & 8171520 & & \\
\hline 2291 & 2 & 9352 & \multirow{3}{*}{2.731} & \multirow{3}{*}{$11.61 \mathrm{C}$} \\
\hline 2292 & 3 & 2198 & & \\
\hline 2293 & 4 & 8048640 & & \\
\hline 2319 & 2 & 7996 & \multirow{3}{*}{2.765} & \multirow{3}{*}{9.925} \\
\hline $2320-2321$ & 3 & 2228 & & \\
\hline 2322 & 4 & 8056832 & & \\
\hline 2775 & 2 & 349952 & \multirow{3}{*}{16.205} & \multirow{3}{*}{357.480} \\
\hline 2776 & 3 & 15864 & & \\
\hline 2777 & 4 & 9789440 & & \\
\hline 2938 & 2 & 341248 & \multirow{3}{*}{15.953} & \multirow{3}{*}{344.550} \\
\hline 2939 & 3 & 15800 & & \\
\hline 2940 & 4 & 9904128 & & \\
\hline
\end{tabular}

Niemann et al. (1996) give an upper limit of $\mathrm{HD} / \mathrm{H}_{2}=(1.1 \pm 0.3) \times 10^{-4}$, corresponding to an atomic ratio of $\mathrm{D} / \mathrm{H}=5.5 \times 10^{-5}$, for gases entering the mass spectrometer via inlet $\mathrm{DL} 2$ during descent at atmospheric pressures of 8.21 to 21 bars. At that time, the ionizing potential was reduced to $15 \mathrm{eV}$ for steps 3960-3967, 4104-4119, and 4211-4222. Under those conditions, there are essentially no He ions (Niemann et al., 1996).

The results are shown in Table 2 for the 2-4 amu mass range. The first three columns of Table 2 are the same as in Table 1. The last two columns of Table 2 are the count ratios normalized to the number of counts at 2 amu. All of the data in Table 2 were taken at an ionization potential of $15 \mathrm{eV}$. Because of this low ionization potential, column 5 of Table 2 shows the lowest observed values for the ratio of counts at $(\mathrm{m} / \mathrm{z}=4)$ relative to those at $(\mathrm{m} / \mathrm{z}=2)$. 
Table 2. Data at $m / z=2,3$ and 4 for gases directly leaked via DL2 into the GPMS at $15 \mathrm{eV}$

\begin{tabular}{|c|c|c|c|c|}
\hline $\begin{array}{c}\text { Step } \\
\text { Number }\end{array}$ & $\begin{array}{c}\text { Mass/charge, } \\
\mathrm{m} / \mathrm{z}\end{array}$ & Counts & $\begin{array}{c}(\mathrm{m} / \mathrm{z}=3) /(\mathrm{m} / \mathrm{z}=2) \\
\times 10^{4}\end{array}$ & $\begin{array}{c}(\mathrm{m} / z=4) /(\mathrm{m} / \mathrm{z}=2) \\
\times 10^{4}\end{array}$ \\
\hline 3960 & 2 & 558592 & \multirow{3}{*}{1.84} & \multirow{3}{*}{1.61} \\
\hline 3961 & 3 & 103 & & \\
\hline 3962 & 4 & 90 & & \\
\hline 3964 & 2 & 527872 & \multirow{3}{*}{2.14} & \multirow{3}{*}{1.46} \\
\hline 3965 & 3 & 113 & & \\
\hline 3966 & 4 & 77 & & \\
\hline 4104 & 2 & 609792 & \multirow{6}{*}{2.01} & \multirow{6}{*}{1.79} \\
\hline 4105 & 2 & 591360 & & \\
\hline 4106 & 3 & 123 & & \\
\hline 4107 & 3 & 119 & & \\
\hline 4108 & 4 & 119 & & \\
\hline 4109 & 4 & 96 & & \\
\hline 4112 & 2 & 589312 & \multirow{3}{*}{2.44} & \multirow{3}{*}{1.60} \\
\hline 4113 & 3 & 144 & & \\
\hline 4114 & 4 & 94 & & \\
\hline 4116 & 2 & 581120 & \multirow{3}{*}{1.88} & \multirow{3}{*}{1.70} \\
\hline 4117 & 3 & 109 & & \\
\hline 4118 & 4 & 99 & & \\
\hline 4211 & 2 & 652800 & \multirow{3}{*}{1.90} & \multirow{3}{*}{1.47} \\
\hline 4212 & 3 & 124 & & \\
\hline 4213 & 4 & 96 & & \\
\hline 4215 & 2 & 621056 & \multirow{3}{*}{2.17} & \multirow{3}{*}{1.72} \\
\hline 4216 & 3 & 135 & & \\
\hline 4217 & 4 & 107 & & \\
\hline 4219 & 2 & 624128 & \multirow{3}{*}{2.08} & \multirow{3}{*}{1.73} \\
\hline 4220 & 3 & 130 & & \\
\hline 4221 & 4 & 108 & & \\
\hline
\end{tabular}

\section{INTERPRETATION}

We believe that the data in Table 1 and Table 2 are the most important sets of observations for determining values of the ${ }^{3} \mathrm{He} /{ }^{4} \mathrm{He}$ and $\mathrm{HD} / \mathrm{H}_{2}$ ratios in Jupiter. Table 1 shows the counts at 2, 3 and $4 \mathrm{amu}$ when the mass spectrometer had the highest ratio of ${ }^{4} \mathrm{He}^{+} / \mathrm{H}_{2}{ }^{+}$ions. Table 2 shows the counts at 2, 3 and 4 amu when the mass spectrometer had the lowest ratio of ${ }^{4} \mathrm{He}^{+} / \mathrm{H}_{2}{ }^{+}$ions.

\subsection{The ${ }^{3} \mathrm{He} /{ }^{4} \mathrm{He}$ Ratio in Jupiter}

Data from Table 1 are plotted as $(\mathrm{m} / \mathrm{z}=3) /(\mathrm{m} / \mathrm{z}=4) \mathrm{vs}(\mathrm{m} / \mathrm{z}=2) /(\mathrm{m} / \mathrm{z}=4)$ in Figure 1. As noted earlier, the $(\mathrm{m} / \mathrm{z}=3) /(\mathrm{m} / \mathrm{z}=4)$ count ratio increased from a value of $\sim 2.5 \times 10^{-4}$ to $\sim 16 \mathrm{x}$ $10^{-4}$ as the value of the $(\mathrm{m} / \mathrm{z}=2) /(\mathrm{m} / \mathrm{z}=4)$ count ratio increased from $\sim 0.0005$ to $\sim 0.035$. Such a correlation is expected if the signals at $2 \mathrm{amu}, 4 \mathrm{amu}$, and $3 \mathrm{amu}$ consist of $\mathrm{H}^{+},{ }^{4} \mathrm{He}^{+}$, and $\left({ }^{3} \mathrm{He}^{+}\right.$plus $\left.\mathrm{HD}^{+}\right)$ions, respectively. In that case, the y intercept at $\mathrm{H}_{2} /{ }^{4} \mathrm{He}=0$ would correspond to the value of the $(\mathrm{m} / \mathrm{z}=3) /(\mathrm{m} / \mathrm{z}=4)$ ratio for pure helium, i.e., it would be the value of the ${ }^{3} \mathrm{He} /{ }^{4} \mathrm{He}$ ratio if the instrument sensitivity is identical for ${ }^{3} \mathrm{He}$ and ${ }^{4} \mathrm{He}$. Likewise, the slope of the line would correspond to the value of the $(\mathrm{m} / \mathrm{z}=3) /(\mathrm{m} / \mathrm{z}=2)$ ratio for pure hydrogen, i.e., it would be the value of the $\mathrm{DH} / \mathrm{H}_{2}$ ratio if there were no reaction producing $\mathrm{H}_{3}{ }^{+}$ions from $\mathrm{H}_{2}$ and 
the instrument sensitivity was identical for $\mathrm{HD}$ and $\mathrm{H}_{2}$. The intercept in Figure 1 is $(2.34 \pm 0.03)$ $\mathrm{x} 10^{-4}$ and the slope is $(3.91 \pm 0.02) \times 10^{-2}$.

\section{Eight Sweeps}

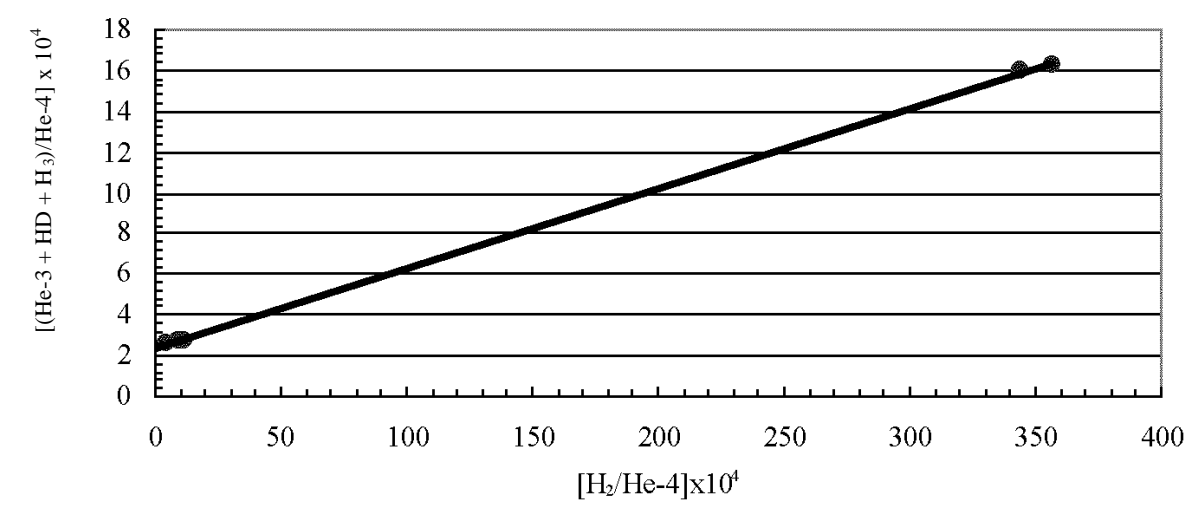

Figure 1. This graph of the raw data from Table 1 illustrates the corrleation between the signals for the 3 amu/4 amu ratio and the signals corresponding to the hydrogen/helium ratio.

Niemann et al. (1996) and Mahaffy et al. (1998) stress the presence of $\mathrm{H}_{3}{ }^{+}$ions in the total counts at $3 \mathrm{amu}$. Thus, the vertical axis in Figure 1 is labeled as $\left[\left(\mathrm{He}-3+\mathrm{HD}+\mathrm{H}_{3}\right) / \mathrm{He}-4\right] \times 10^{4}$. They note that $\mathrm{H}_{3}{ }^{+}$ions are produced by the dissociative ionization of $\mathrm{CH}_{4}$ and by ion- molecule reactions on $\mathrm{H}_{2} \cdot \mathrm{H}_{3}{ }^{+}$ions from reactions on $\mathrm{H}_{2}$ should disappear when the $\mathrm{H}_{2} /{ }^{4} \mathrm{He}$ ratio goes to zero. To correct for $\mathrm{H}_{3}{ }^{+}$from $\mathrm{CH}_{4}{ }^{+}$, we use a value of $\mathrm{H}_{3}{ }^{+} / \mathrm{CH}_{4}{ }^{+}=1.85 \times 10^{-5}$ as the fraction of $\mathrm{CH}_{4}$ counts that contribute to the counts at 3 amu for the NGC and EC1 data shown in Table 1 (Mahaffy et al., 1998). The signal at 16 amu, as measured at steps 2180, 2381, 2790 and 2952, increased by about $16 \%$ during the time span represented by the data in Table 1 . From the value of $\mathrm{H}_{3}{ }^{+} / \mathrm{CH}_{4}{ }^{+}=1.85 \times 10^{-5}$, we estimate the counts of $\mathrm{H}_{3}{ }^{+}$ions from $\mathrm{CH}_{4}{ }^{+}$to be $124,132,134$, $135,135,138,141$, and 143 counts when the signal at 3 amu was counted in step numbers 2166, $2254,2279,2289,2292,2320-2321,2776$, and 2939, respectively.

Figure 2 shows the correlation of $(\mathrm{m} / \mathrm{z}=3) /(\mathrm{m} / \mathrm{z}=4)$ with $(\mathrm{m} / \mathrm{z}=2) /(\mathrm{m} / \mathrm{z}=4)$ after the above correction for the contribution of $\mathrm{CH}_{4}$ to $\mathrm{H}_{3}{ }^{+}$ions. The vertical axis in Figure 2 is still labeled as $\left[\left(\mathrm{He}-3+\mathrm{HD}+\mathrm{H}_{3}\right) / \mathrm{He}-4\right] \times 10^{4}$. Although the contribution of $\mathrm{H}_{3}{ }^{+}$ions from $\mathrm{CH}_{4}$ was subtracted from the total count at $3 \mathrm{amu}$, there may still be a contribution of $\mathrm{H}_{3}{ }^{+}$ions from the ion-molecule reaction on $\mathrm{H}_{2}$. If so, that will tend to increase the slope of the line in Figure 2 and make it higher than the value of the $\mathrm{HD} / \mathrm{H}_{2}$ ratio. The vertical intercept in Figure 2 suggests that pure Jovian helium, free of interference from $\mathrm{HD}$ and $\mathrm{H}_{3}$, has ${ }^{3} \mathrm{He} /{ }^{4} \mathrm{He}=(2.17 \pm 0.03) \times 10^{-4}$. 


\section{Eight Sweeps, corrected}

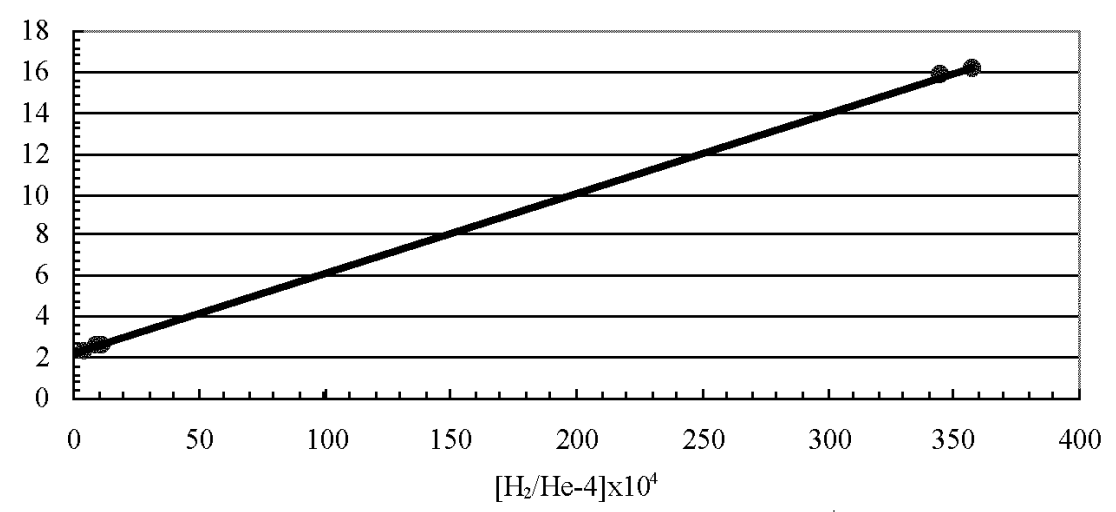

Figure 2. This graph represents Figure 1 after correction for $\mathrm{H}_{3}{ }^{+}$interference.

The slope of the line in Figure 2 is $(3.92 \pm 0.02) \times 10^{-2}$. This is $\sim 3$ orders-of-magnitude steeper than the slope expected from HD interference if ${ }^{2} \mathrm{H} /{ }^{1} \mathrm{H}=(2.6 \pm 0.7) \times 10^{-5}$ (Mahaffy et al., 1998) and $\sim 2$ orders-of-magnitude steeper than the slope expected from HD if ${ }^{2} \mathrm{H} /{ }^{1} \mathrm{H}^{\sim} 1.0 \mathrm{x}$ $10^{-4}$. Large isotopic fractionation effects are expected in chemical and physical reactions involving hydrogen because it has the largest isotopic mass ratio of any element (Geiss and Reeves, 1981). Thus, the processed hydrogen gas from NGC and EC1 may be enriched in HD so that the vertical component of the line slopes in Figures 1 and 2 represents a mixture of counts from $\mathrm{HD}^{+}$ions at $3 \mathrm{amu}$ with the product of ion molecule reactions on $\mathrm{H}_{2}$ that also produce counts of $\mathrm{H}_{3}{ }^{+}$ions at $3 \mathrm{amu}$.

Interference from $\mathrm{H}_{3}{ }^{+}$ions produced by the ion-molecule reaction on $\mathrm{H}_{2}$ might be reduced by using only the gas from NGC, before the cell was heated to drive off trapped $\mathrm{H}_{2}$. Niemann et al. (1996, p. 847) state that, "During probe descent, the ${ }^{3} \mathrm{He}{ }^{A} \mathrm{He}$ ratio was determined from 3 amu and 4 ати data obtained with the noble gas cell (NGC) sample (6). Hydrogen was effectively absent from this gas sample." This NGC sample is represented by first six scans (steps 21652232) in Table 1.

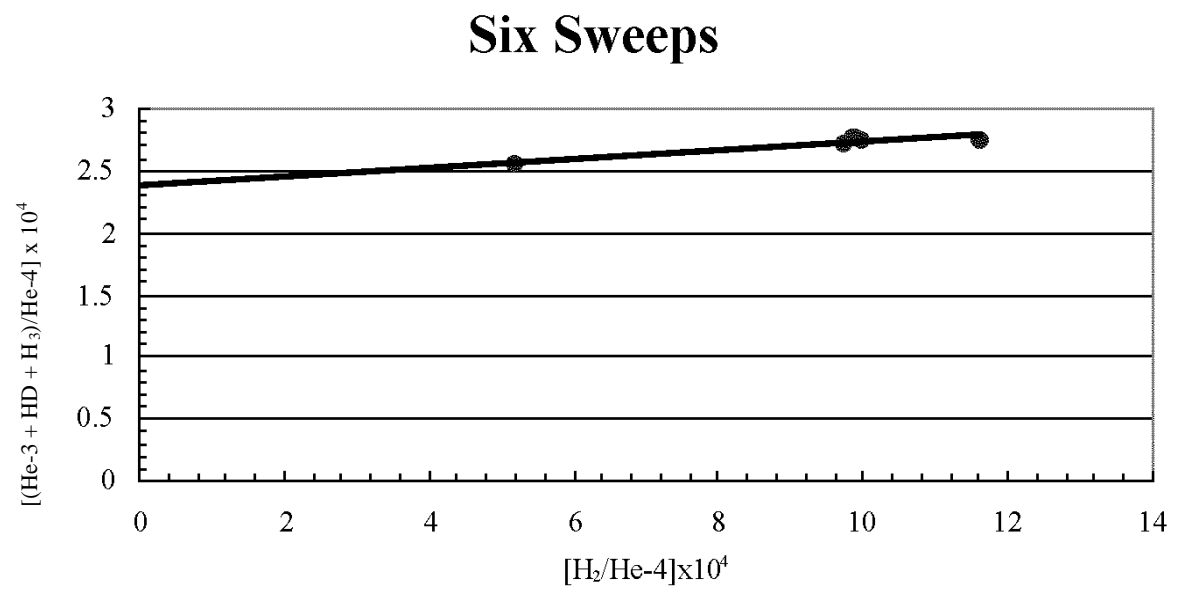

Figure 3. This graph of raw data for only the first six sweeps from Table 1 shows the same correlation and intercept, within experimental error, as in Figure 1. 
Figure 3 shows the correlation of $(m / z=3) /(m / z=4)$ with $(m / z=2) /(m / z=4)$ for these first six scans of the NGC sample, with no correction for the contribution of $\mathrm{CH}_{4}$ to $\mathrm{H}_{3}{ }^{+}$ions. The vertical intercept in Figure 3 suggests an upper limit of ${ }^{3} \mathrm{He} /{ }^{4} \mathrm{He}=(2.39 \pm 0.08) \times 10^{-4}$. The slope of the line in Figure 3, $(3.5 \pm 0.8) \times 10^{-2}$, is poorly defined because of the very limited range of values in the first six sweeps.

\section{Six Sweeps, corrected}

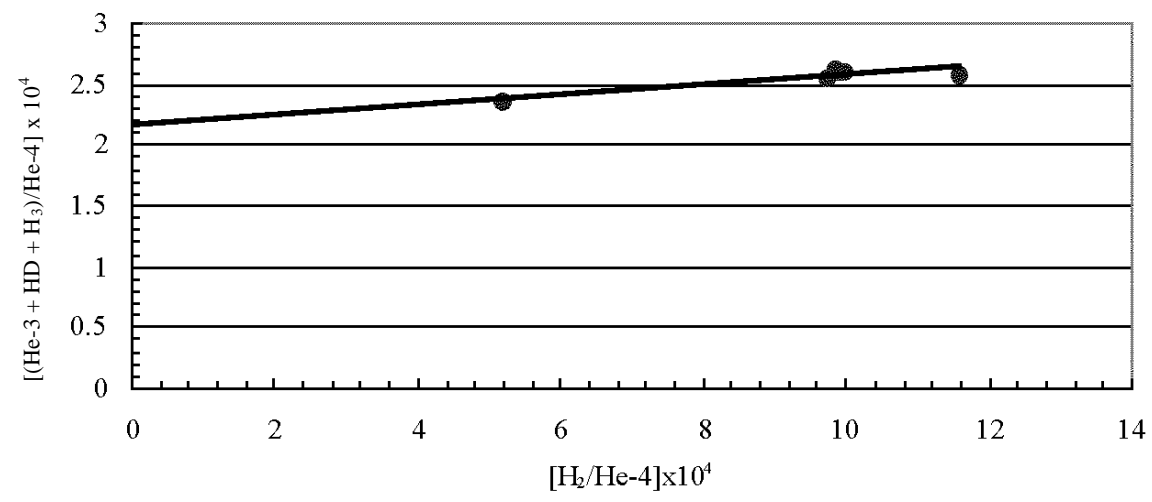

Figure 4. This graph represents Figure 3 after correction for $\mathrm{H}_{3}{ }^{+}$interference.

Figure 4 shows the correlation of $(\mathrm{m} / \mathrm{z}=3) /(\mathrm{m} / \mathrm{z}=4)$ with $(\mathrm{m} / \mathrm{z}=2) /(\mathrm{m} / \mathrm{z}=4)$ for the first six scans in Table 1 (the NGC sample) after a value of $\mathrm{H}_{3}{ }^{+} / \mathrm{CH}_{4}=1.85 \times 10^{-5}$ (Mahaffy et al., 1998) was used to correct for the contribution of $\mathrm{CH}_{4}$ to $\mathrm{H}_{3}{ }^{+}$ions. This correction did not improve the uncertainty on the intercept or the slope. The intercept in Figure 4 yields a value of ${ }^{3} \mathrm{He} /{ }^{4} \mathrm{He}=$ $(2.15 \pm 0.09) \times 10^{-4}$. The slope of the line in Figure 4 is $(4 \pm 1) \times 10^{-2}$.

As noted, values of the intercepts and the slopes in Figures 3 and 4 are indistinguishable from those in Figures 1 and 2, respectively. This means that interference at 3 amu from $\mathrm{HD}^{+}$and $\mathrm{H}_{3}{ }^{+}$ ions, produced by the ion-molecule reaction on $\mathrm{H}_{2}$, was not significantly reduced by using only the gas from NGC.

From the data in Table 1 and Figures $1-4$ we conclude that the best value for the ${ }^{3} \mathrm{He} /{ }^{4} \mathrm{He}$ ratio in Jupiter is $(2.17 \pm 0.03) \times 10^{-4}$ (See Figure 2). Eliminating data from the last two sweeps increases the uncertainty but does not significantly change the value of the ${ }^{3} \mathrm{He} /{ }^{4} \mathrm{He}$ ratio (See Figures 3 and 4$) .{ }^{3} \mathrm{He} /{ }^{4} \mathrm{He}=(2.17 \pm 0.03) \times 10^{-4}$ is about a factor of 2 higher than the value reported by Niemann et al. (1996) and 31\% higher than the value concluded by Mahaffy et al. (1998).

In computing the above values for the ${ }^{3} \mathrm{He} /{ }^{4} \mathrm{He}$ ratio, we assumed that the mass spectrometer sensitivity is identical for ${ }^{3} \mathrm{He}$ and ${ }^{4} \mathrm{He}$. This seems to be a reasonable assumption. Mahaffy et al. (1998) used a refurbished Engineering Unit (EU) to duplicate the performance of the Flight Unit (FU). They report (Mahaffy et al., 1998, p. 257) that "Additional EU experiments show that the instrument response to the two helium isotopes introduced to the ion source in the molecular flow regime is flat for ${ }^{3} \mathrm{He}$ and ${ }^{4} \mathrm{He}$ so this count ratio represents a measure of the Jovian ${ }^{3} \mathrm{He} /{ }^{4} \mathrm{He}$ ratio." 


\subsection{The ${ }^{2} \mathbf{H} /{ }^{1} \mathbf{H}$ Ratio in Jupiter}

As noted above, slopes of the lines in Figures 1-4 suggest that counts at 3 amu from $\mathrm{HD}^{+}$ions and $\mathrm{H}_{3}{ }^{+}$ions amount to $\sim 4 \%$ of the counts from $\mathrm{H}_{2}$ at 2 amu for the operational conditions used to obtain the data shown in Table 1 . This instrumental barrier, with $(\mathrm{m} / \mathrm{z}=3) /(\mathrm{m} / \mathrm{z}=2)=4 \times 10^{-}$ ${ }^{2}$, prevents use of the data in Table 1 to determine if the $\mathrm{HD} / \mathrm{H}_{2}$ ratio in Jupiter is $\sim 10^{-4}$, as seen for hydrogen here on Earth and in most phases of meteorites, or ${ }^{\sim} 10^{-5}$ as seen in some meteorite phases and as proposed for the protosolar nebula, for atmospheres of the Jovian planets, and for primordial galactic hydrogen (Geiss and Reeves, 1981; Geiss, 1993).

In addition to interference at $3 \mathrm{amu}$ from $\mathrm{H}_{3}{ }^{+}$ions, measurement of the $\mathrm{HD} / \mathrm{H}_{2}$ ratio is also hindered by the presence of ${ }^{3} \mathrm{He}^{+}$ions. Fortunately, interference from ${ }^{3} \mathrm{He}^{+}$and $\mathrm{H}_{3}{ }^{+}$ions are both diminished by reducing the electron energy in the ion source. Niemann et al. (1996) used gases entering the mass spectrometer via inlet DL2, when analyzed with a reduced electron energy in the ion source, to obtain an upper limit of $\mathrm{HD} / \mathrm{H}_{2}=(1.1 \pm 0.3) \times 10^{-4}$. Table 2 shows the data obtained when the ionizing potential was reduced to $15 \mathrm{eV}$. Under those conditions, no He ions were produced and Niemann et al. (1996) assumed that there was also "no $\mathrm{H}_{3}{ }^{+}$production" (p. 847).

If there is no interference from $\mathrm{H}_{3}{ }^{+}$for the data tabulated in Table 2, then it appears that $\mathrm{HD} / \mathrm{H}_{2}=(2.1 \pm 0.2) \times 10^{-4}$ if the mass spectrometer sensitivity is identical for HD and $\mathrm{H}_{2}$. This is the average value for the ratio of signals, $(\mathrm{m} / \mathrm{z}=3) /(\mathrm{m} / \mathrm{z}=2)$, for the data shown in Table 2 . This value of the $\mathrm{HD} / \mathrm{H}_{2}$ molecular ratio is equivalent to a value of ${ }^{2} \mathrm{H} /{ }^{1} \mathrm{H}^{\sim} 1.0 \times 10^{-4}$ for the atomic ratio.

The values obtained here for the $\mathrm{HD} / \mathrm{H}_{2}$ and ${ }^{2} \mathrm{H} /{ }^{1} \mathrm{H}$ ratios are about a factor of 2 higher than those reported by Niemann et al. (1996). This might be attributed to a factor of 2 difference in the sensitivity of the mass spectrometer for $\mathrm{HD}$ and $\mathrm{H}$, although we found no mention of this instrumental discrimination in the report by Niemann et al. (1996).

Mahaffy et al. (1998, p. 257) state that, "Final corrections to the [3]/[2] ratio to reflect the $\mathrm{HD} / \mathrm{H}_{2}$ abundance arise from instrumental discrimination between $\mathrm{HD}$ and $\mathrm{H}_{2}$. This effect is approximately $10 \mathrm{in} \mathrm{Ll}$ as determined from introduction of a known mixture of $\mathrm{HD}$ and $\mathrm{H}_{2}$ into the EU L1. It is even higher in L2..." The gases used here to estimate the $\mathrm{HD} / \mathrm{H}_{2}$ (Table 2) entered the mass spectrometer via L2 and might therefore exhibit an instrumental discrimination factor between $\mathrm{HD}$ and $\mathrm{H}_{2}$ that is $>10$.

However, application of the instrumental discrimination factor reported by Mahaffy et al. (1998) to the data in Table 2 does not yield the value of ${ }^{2} \mathrm{H} /{ }^{1} \mathrm{H}$ reported by Mahaffy et al. (1998). Use of an instrumental discrimination factor $>10$ on the data in Table 2 would indicate a value of ${ }^{2} \mathrm{H} /{ }^{1} \mathrm{H}<1.0 \times 10^{-5}$. This is significantly less than the value of ${ }^{2} \mathrm{H} /{ }^{1} \mathrm{H}=(2.6 \pm 0.7) \times 10^{-5}$ reported by Mahaffy et al. (1998).

\section{DISCUSSION AND CONCLUSION}

The value concluded here for the ${ }^{3} \mathrm{He} /{ }^{4} \mathrm{He}$ ratio in Jupiter, $2.2 \times 10^{-4}$, is higher than that of the ${ }^{3} \mathrm{He} /{ }^{4} \mathrm{He}$ ratio in primitive meteorites, 1.4-1.5 x 10 ${ }^{-4}$ (Manuel and Hwaung, 1983; Geiss, 1993). The difference between the ${ }^{3} \mathrm{He} /{ }^{4} \mathrm{He}$ ratio in primitive meteorites and in the Jovian atmosphere may indicate: a) selective enrichment of lighter mass helium isotope in the upper atmosphere of Jupiter, or b) selective loss of the lighter mass isotope from meteorite minerals. Thus, a value of 
${ }^{3} \mathrm{He} /{ }^{4} \mathrm{He}=2.2 \times 10^{-4}$ in Jupiter is credible, although it is a factor of 2 higher than the value reported by Niemann et al. (1996).

The value concluded here for the ${ }^{2} \mathrm{H} /{ }^{1} \mathrm{H}$ ratio in Jupiter, $\sim 1.0 \times 10^{-4}$, lies at the lower end of the range of values reported for the ${ }^{2} \mathrm{H} /{ }^{1} \mathrm{H}$ ratio in meteorites, $(0.9-11) \times 10^{-4}$ (Robert et al., $1987 \mathrm{a}, \mathrm{b})$. This value for the ${ }^{2} \mathrm{H} /{ }^{1} \mathrm{H}$ ratio in Jupiter is almost a factor of 4 higher than the value that Geiss (1993) concludes for the protosolar nebula, but it is within the range of values reported for the primordial ${ }^{2} \mathrm{H} /{ }^{1} \mathrm{H}$ ratio in intergalactic gas clouds at high redshifts (Songaila, et al., 1997; Webb et al., 1997).

The value of ${ }^{2} \mathrm{H} /{ }^{1} \mathrm{H}^{\sim} 1.0 \times 10^{-4}$ in Jupiter is a factor of 2 higher than that reported by Niemann et al. (1996), ${ }^{2} \mathrm{H} /{ }^{1} \mathrm{H}=(5 \pm 2) \times 10^{-5}$, and almost a factor of 4 higher than the value reported by Mahaffy et al. $(1998),{ }^{2} \mathrm{H} /{ }^{1} \mathrm{H}=(2.6 \pm 0.7) \times 10^{-5}$.

It should be stressed that values reported for the ${ }^{2} \mathrm{H} /{ }^{1} \mathrm{H}$ ratio depend on the count ratio at $(\mathrm{m} / \mathrm{z}$ $=3) /(\mathrm{m} / \mathrm{z}=2)$ arising from the ionic $\mathrm{HD}^{+} / \mathrm{H}_{2}{ }^{+}$ratio. Table 2 shows the lowest measured count ratios at $(\mathrm{m} / \mathrm{z}=3) /(\mathrm{m} / \mathrm{z}=2)$ in the raw GPMS data on the internet at http://webserver.gsfc.nasa.gov/code915/ gpms/datasets/gpmsdata.html. So far as we know, the GPMS team observed no sample in Jupiter with $(\mathrm{m} / \mathrm{z}=3) /(\mathrm{m} / \mathrm{z}=2)<10^{-4}$.

Niemann et al. (1996) and Mahaffy et al. (1998) have much more detailed information on the operation of the GPMS than we and should therefore have more reliable values for isotopic ratios. However, the lowest values observed for the $(\mathrm{m} / \mathrm{z}=3) /(\mathrm{m} / \mathrm{z}=2)$ count ratio are included in Table 2, and the instrumental discrimination factor reported by Mahaffy et al. (1998) does not appear to make those data agree with the value that Mahaffy et al. (1998) report for Jupiter's ${ }^{2} \mathrm{H} /{ }^{1} \mathrm{H}$ ratio.

The average terrestrial ${ }^{2} \mathrm{H} /{ }^{1} \mathrm{H}$ ratio is $1.6 \times 10^{-4}$. Relative to terrestrial hydrogen, that in Jupiter displays a value of $\delta \mathrm{D}^{\sim}-375 \%$. This is similar to the low- $\delta \mathrm{D}$ hydrogen that Robert $e t$ al. (1987a) reported in the amorphous matrix surrounding chondrules of the Chainpur chondritic meteorite.

Finally, abundances of $\mathrm{H}$ and $\mathrm{He}$ isotopes in Jupiter can be compared with predictions of the supernova and the nebular models for the formation of the solar system. The first imagines that the solar system inherited most of its chemical and isotopic irregularities directly from heterogeneous supernova (SN) debris (Manuel and Sabu, 1975, 1977). The inner planets consist mostly of $\mathrm{Fe}$ and other elements from the $\mathrm{SN}$ interior; the outer planets consist mostly of $\mathrm{H}, \mathrm{He}$ and other elements that remained in the cooler, outer SN layers.

The nebular model suggests that the entire solar system formed from a homogeneous cloud and secondary processes made the present chemical and isotopic heterogeneities (Wood, 1999). According to the nebular model, the earth and other rocky planets with iron-rich cores were produced in the inner part of the solar system by chemical differentiation and loss of volatile elements like H, He and C. Nuclear reactions in the sun converted D into ${ }^{3} \mathrm{He}$ (Geiss, 1993), but the composition of the protosolar nebula has been preserved in giant, gaseous planets like Jupiter and Saturn that reside outside the asteroid belt.

Niemann et al. (1996) and Mahaffy et al. (1998) claim that differences in abundances of $\mathrm{H}$ and $\mathrm{He}$ isotopes in Jupiter and in the solar wind (SW) agree with predictions of the nebular model for forming the solar system. For example, the first report of results from the Galileo Probe Mass Spectrometer measurement of Jupiter states that, "Together, the D/H and ${ }^{3} \mathrm{He}{ }^{4} \mathrm{He}$ ratios are consistent with conversion in the sun of protosolar deuterium to present-day ${ }^{3} \mathrm{He} . "$ (Niemann et al., 1996, p. 846, last sentence of abstract). The values of both isotope ratios were later changed, but the conclusion remained the same: "We have established the anticipated result 
that Jupiter indeed represents a repository of solar nebula material unmodified by nuclear reactions for the last 4.55 Gy." (Mahaffy et al., 1998, pp. 261-262).

If Jupiter and the sun initially formed out of the same material and only deuterium burning altered the abundances of nuclides at the solar surface, then the value of the ${ }^{3} \mathrm{He} /{ }^{4} \mathrm{He}$ ratio there today would be the same as that of the $\left({ }^{2} \mathrm{H}+{ }^{3} \mathrm{He}\right) /{ }^{4} \mathrm{He}$ ratio in the starting material. Table $3 \mathrm{a}$ shows values expected for the ${ }^{3} \mathrm{He} /{ }^{4} \mathrm{He}$ ratio in the sun today if deuterium burning acted on Jupiter-like starting material with the ${ }^{4} \mathrm{He} / \mathrm{H}_{2}$ ratio reported by Niemann et al. (1996) and isotopic compositions reported in Niemann et al. (1996), in Mahaffy et al. (1998), and in this paper.

Table 3a. Solar values expected for ${ }^{3} \mathrm{He} /{ }^{4} \mathrm{He}$ after deuterium burning of Jupiter-like material

\begin{tabular}{|c|c|c|c|}
\hline Reference & Initial Composition & After D-burning & ${ }^{3} \mathrm{He} /{ }^{4} \mathrm{He}$ \\
\hline Niemann et al. $(1996)$ & ${ }^{1} \mathrm{H}=10000 ;{ }^{2} \mathrm{H}=0.50$ & ${ }^{1} \mathrm{H}=10000 ;{ }^{2} \mathrm{H}=0.00$ & $7.5 \times 10^{-4}$ \\
& ${ }^{4} \mathrm{He}=780 ;{ }^{3} \mathrm{He}=0.086$ & ${ }^{4} \mathrm{He}=780 ;{ }^{3} \mathrm{He}=0.59$ & \\
\hline Mahaffy et al. $(1998)$ & ${ }^{1} \mathrm{H}=10000 ;{ }^{2} \mathrm{H}=0.26$ & ${ }^{1} \mathrm{H}=10000 ;{ }^{2} \mathrm{H}=0.00$ & $5.0 \times 10^{-4}$ \\
& ${ }^{4} \mathrm{He}=780 ;{ }^{3} \mathrm{He}=0.13$ & ${ }^{4} \mathrm{He}=780 ;{ }^{3} \mathrm{He}=0.39$ & \\
\hline This work & ${ }^{1} \mathrm{H}=10000 ;{ }^{2} \mathrm{H} \sim 1.0$ & ${ }^{1} \mathrm{H}=10000 ;{ }^{2} \mathrm{H}=0.00$ & $\sim 15 \times 10^{-4}$ \\
& ${ }^{4} \mathrm{He}=780 ;{ }^{3} \mathrm{He}=0.17$ & ${ }^{4} \mathrm{He}=780 ;{ }^{3} \mathrm{He} \sim 1.17$ & \\
\hline
\end{tabular}

The solar value of the ${ }^{3} \mathrm{He} /{ }^{4} \mathrm{He}$ ratio is usually assumed to be that in the solar wind (SW), where ${ }^{3} \mathrm{He} /{ }^{4} \mathrm{He}^{\sim} 4 \times 10^{-4}$ (Geiss and Bochsler, 1991; Manuel and Hwaung, 1983). Deuterium burning of Jupiter-like material as described in the first GPMS report would produce ${ }^{3} \mathrm{He} /{ }^{4} \mathrm{He}=$ $7.5 \times 10^{-4}$ (Upper right section of Table 3a). Because of large errors on isotopic ratios in the first GPMS report (Niemann et al., 1996), this is within error limits of the $\mathrm{SW}{ }^{3} \mathrm{He} /{ }^{4} \mathrm{He}$ ratio. There were smaller errors in the revised GPMS report (Mahaffy et al., 1998). Deuterium burning of this material would produce ${ }^{3} \mathrm{He} /{ }^{4} \mathrm{He}=5.0 \times 10^{-4}$ (Middle right section of Table 3a), and might indicate better agreement of the nebular model with the $\mathrm{SW}{ }^{3} \mathrm{He} /{ }^{4} \mathrm{He}$ ratio. However, deuterium burning of material with the ${ }^{3} \mathrm{He} /{ }^{4} \mathrm{He}$ and the ${ }^{2} \mathrm{H} /{ }^{1} \mathrm{H}$ ratios concluded here would not yield the ${ }^{3} \mathrm{He} /{ }^{4} \mathrm{He}$ ratio observed in the solar wind (Lower right section of Table 3a). Deuterium burning of this material would produce $\sim 4$ times the value of the ${ }^{3} \mathrm{He} /{ }^{4} \mathrm{He}$ ratio in the solar wind.

Saturn might be used instead of Jupiter to represent the composition of the solar nebula. There have been no direct measurements on isotopic ratios of $\mathrm{H}$ and $\mathrm{He}$ in Saturn. However, Voyager measurements indicate a much lower value of the ${ }^{4} \mathrm{He} / \mathrm{H}_{2}$ ratio in Saturn than in Jupiter (Conrath et al., 1984). Table $3 \mathrm{~b}$ shows values expected for the ${ }^{3} \mathrm{He} /{ }^{4} \mathrm{He}$ ratio in the sun today if deuterium burning acted on Saturn-like starting material with the ${ }^{4} \mathrm{He} / \mathrm{H}_{2}$ ratio reported by Conrath et al. (1984) and the isotopic compositions reported in Jupiter by Niemann et al. (1996), Mahaffy et al. (1998), and this paper.

Table $3 b$. Solar values expected for ${ }^{3} \mathrm{He} /{ }^{4} \mathrm{He}$ after deuterium burning of Saturn-like material

\begin{tabular}{|l|l|l|l|}
\hline Reference & Initial Composition & After D-burning & ${ }^{3} \mathrm{He} /{ }^{4} \mathrm{He}$ \\
\hline Niemann et al. $(1996)$ & ${ }^{1} \mathrm{H}=10000 ;{ }^{2} \mathrm{H}=0.50$ & ${ }^{1} \mathrm{H}=10000 ;{ }^{2} \mathrm{H}=0.00$ & $30 \times 10^{-4}$ \\
Conrath et al. $(1984)$ & ${ }^{4} \mathrm{He}=172 ;{ }^{3} \mathrm{He}=0.019$ & ${ }^{4} \mathrm{He}=172 ;{ }^{3} \mathrm{He}=0.52$ & \\
\hline Mahaffy et al. $(1998)$ & ${ }^{1} \mathrm{H}=10000 ;{ }^{2} \mathrm{H}=0.26$ & ${ }^{1} \mathrm{H}=10000 ;{ }^{2} \mathrm{H}=0.00$ & $17 \times 10^{-4}$ \\
Conrath et al. $(1984)$ & ${ }^{4} \mathrm{He}=172 ;{ }^{3} \mathrm{He}=0.028$ & ${ }^{4} \mathrm{He}=172 ;{ }^{3} \mathrm{He}=0.29$ & \\
\hline This work & ${ }^{1} \mathrm{H}=10000 ;{ }^{2} \mathrm{H} \sim 1.0$ & ${ }^{1} \mathrm{H}=10000 ;{ }^{2} \mathrm{H}=0.00$ & $\sim 60 \times 10^{-4}$ \\
Conrath et al. $(1984)$ & ${ }^{4} \mathrm{He}=172 ;{ }^{3} \mathrm{He}=0.037$ & ${ }^{4} \mathrm{He}=172 ;{ }^{3} \mathrm{He}=1.037$ & \\
\hline
\end{tabular}

Proceedings of the 1999 ACS Symposium (organized by Glenn Seaborg and O. Manuel): The Origin of Elements in the Solar System: Implications of Post-1957 Observations

(O. Manuel, editor, Kluwer/Plenum Pub., 2000) pp. 529-543. 
It can be seen from the right column of Table $3 b$ that deuterium burning of Saturn-like material would, for all three estimates of the initial $\mathrm{H}$ and $\mathrm{He}$ ratios, produce ${ }^{3} \mathrm{He} /{ }^{4} \mathrm{He}$ ratios that are higher than that observed in the solar wind.

From Tables 3a and 3b, we conclude that the Galileo Probe Mass Spectrometer provides no evidence in support of the nebular model for forming the solar system. The ${ }^{3} \mathrm{He} /{ }^{4} \mathrm{He}$ and ${ }^{2} \mathrm{H} /{ }^{1} \mathrm{H}$ ratios in Jupiter are so high that deuterium burning of this material would produce more ${ }^{3} \mathrm{He}$ than is observed in the solar wind. Jupiter formed from elements with some of the same chemical and isotopic heterogeneities seen in meteorites, including hydrogen and strange xenon (Manuel et al., 1998). The discrepancy between observations and the nebular model increases if Saturn-like material formed the sun.

Conrath et al. (1984) and other proponents of the nebular model claim that the lower value of the ${ }^{4} \mathrm{He} / \mathrm{H}_{2}$ ratio in Saturn may indicate that He may have migrated to the core of that planet in the same fashion they imagine Fe may have migrated to the core of the earth and other rocky planets. According to this view Jupiter has been spared the fate suffered by other planets and remains as proof of the nebular model: "Thus, helium differentiation appears to have not yet begun in Jupiter, and the atmospheric helium abundance should be representative of the bulk composition of the planet." (Conrath et al., 1984, p. 807).

The nebular model was a useful assumption when the classical papers on stellar nucleosynthesis were published (Burbidge et al., 1957; Cameron, 1957). However, it has outlived its usefulness and cannot be sustained by such ad hoc explanations for the multitude of discordant observations since 1957, including the results presented in many other papers at this symposium and those from the Galileo Probe Mass Spectrometer shown here in Tables 1-3 and in Figures 1-4.

\section{REFERENCES}

Bernatowicz, T.J. and Podosek, F.A.: 1978, "Nuclear components in the atmosphere", in Terrestrial Rare Gases, eds., Alexander, Jr., E.C. and Ozima, M., Center for Academic Publications Press, Tokyo, pp. 99-135.

Burbidge, E.M., Burbidge, G.R., Fowler, W.A. and Hoyle, F.: 1957, "Synthesis of the elements in stars", Rev. Mod. Phys. 29, 547-650.

Cameron, A.G. W.: 1957, "Nuclear reactions in stars and nucleosynthesis", Publ. Astron. Soc. Pac. 69, $201-222$.

Chapman, S. and Cowling, T.G.: 1952, The Mathematical Theory of Non-Uniform Gases, Cambridge University Press, Cambridge, $431 \mathrm{pp}$.

Conrath, B.J., Gautier, D., Hanel, R.A. and Hornstein, J.S.: 1984, "The helium abundance of Saturn from Voyager measurements", Ap. J. 282, 807-815.

Geiss, J.: 1993, "Primordial abundance of hydrogen and helium isotopes", in Origin and Evolution of the Elements, eds., Prantzos, N., Vangioni-Flam, E. and Cassè, M., Cambridge University Press, Cambridge, pp. 89-106.

Geiss, J. and Bochsler, P.: 1991, "Long-term variations in solar wind properties. Possible causes versus observations", in The Sun in Time, eds. Sonnett, C.P., Giampapa, M.S., and Matthews, M.S., Univ. Arizona Press, pp. 98-117.

Geiss, J. and Reeves, H.: 1981, "Deuterium in the solar system”, Astron. Astrophys. J. 93, 189-199.

Kaiser, W.A.: 1972, "Rare gas studies in Luna-16-G-7 fines by stepwise heating technique. A low fission solar wind xenon", Earth Planet. Sci. Lett. 13, 387-399.

Mahaffy, P.R., Donahue, T.M., Atreya, S.K., Owen, T.C. and Niemann, H.B.: 1998, "Galileo probe measurements of D/H and ${ }^{3} \mathrm{He} /{ }^{4} \mathrm{He}$ in Jupiter's atmosphere", Space Science Reviews, 84, 251-263.

Manuel, O.K. and Hwaung, G.: 1983, "Solar abundances of the elements", Meteoritics 18, 209-222.

Manuel, O.K. and Sabu, D.D.: 1975, "Elemental and isotopic inhomogeneities in noble gases: The case for local synthesis of the chemical elements", Trans. Missouri Acad. Sci. 9, 104-122.

Manuel, O.K. and Sabu, D.D.: 1977, "Strange xenon, extinct superheavy elements and the solar neutrino puzzle", Science 195, 208-209.

Manuel, O., Windler, K., Nolte, A., Johannes, L., Zirbel, J. and Ragland, D.: 1998, "Strange xenon in Jupiter”, J. Radioanal. Nucl. Chem. 238, 119-121.

Proceedings of the 1999 ACS Symposium (organized by Glenn Seaborg and O. Manuel): The Origin of Elements in the Solar System: Implications of Post-1957 Observations

(O. Manuel, editor, Kluwer/Plenum Pub., 2000) pp. 529-543. 
Niemann, H.B., Atreya, S.K., Carignan, G.R., Donahue, T.M., Haberman, J.A., Harpold, D.N., Hartle, R.E., Hunten, D.M., Kasprzak, W.T., Mahaffy, P.R., Owen, T.C., Spencer, N.W. and Way, S.H.: 1996, "The Galileo probe mass spectrometer: Composition of Jupiter's atmosphere", Science 272, 846-848.

Robert, F., Javoy, M., Halbout, J., Dimon, B. and Merlivat, L.: 1987a, "Hydrogen isotope abundances in the solar system. Part I. Unequilibrated chondrites", Geochim. Cosmochim. Acta 51, 1787-1805.

Robert, F., Javoy, M., Halbout, J., Dimon, B. and Merlivat, L.: 1987b, "Hydrogen isotope abundances in the solar system. Part II. Meteorites with terrestrial-like D/H ratio", Geochim. Cosmochim. Acta, 51, 1807-1822.

Songaila, A., Wampler, E.J. and Cowie, L.L.: 1997, "A high deuterium abundance in the early universe", Nature 385, 137-139.

Webb, J.K., Carswell, R.F., Lanzetta, K.M., Ferlet, R., Lemoine, M, Vidal-Madjar, A. and Bowen, D.V.: 1997, “A high deuterium abundance at redshift $\mathrm{z}=0.7$ ", Nature 388, 250-252.

Wiens, R.C., Huss, G.R. and Burnett, D.S.: 1999, "The solar system oxygen-isotopic composition: Predication and implications for solar nebula processes", Meteoritics. Planet. Sci. 34, 99-107.

Wood, J.A.: 1999, "Forging the planets: The origin of our solar system", Sky and Telescope, 97, 36-48.

Proceedings of the 1999 ACS Symposium (organized by Glenn Seaborg and O. Manuel): The Origin of Elements in the Solar System: Implications of Post-1957 Observations

(O. Manuel, editor, Kluwer/Plenum Pub., 2000) pp. 529-543. 